\title{
Universidad y un nuevo orden espiritual: el caso de la FUCI 1933-1939
}

\author{
Jorge Dagnino Jiménez. \\ INSTITUTO DE HISTORIA \\ PONTIFICIA UNIVERSIDAD CATÓLICA DE CHILE
}

\section{Introducción}

Este artículo versa sobre la influencia de la FUCI (Federazione Universitaria Cattolica Italiana) en el período 1933-1939 en la búsqueda y elaboración de un nuevo orden espiritual, basado en una nueva concepción de Iglesia y modelos de santidad, así como también un modelo de militancia total, en el esfuerzo, por parte de esta federación, de elaborar un sentido de modernidad católica, aspecto que ha tendido a ser descuidado por los investigadores que se han concentrado en la formación de futura clase dirigente democrata cristiana. ${ }^{1} \mathrm{El}$ artículo parte examinando lo que estos católicos entendían por catolicismo totalitario en la época, para después revisar la fundamental importancia de la construcción de la personalidad religiosa, particularmente a través de las virtudes de la amistad y de la ca-

1 Aldo Moro, Giulio Andreotti, Amintore Fanfani, Guido Gonella, Mario Scelba, Paolo Emilio Taviani, Mariano Rumor, por nombrar a algunos, fueron formados y educados en la asociación. Además, Giovanni Battista Montini, el futuro Papa Pablo VI fue Asistente Eclesiástico de la federación entre 1925 y 1933. Para la historia de la FUCI, que ha tendido a concentrarse en el período de Montini, véase, por ejemplo, M.L. Paronetto Valier, Competenze e responsabilità. Spiritualità delle professioni, (Roma, 2002); M.C. Giuntella, La Fuci tra Modernismo, Partito Popolare e Fascismo (Roma, 2000); R.J. WolfF, Between Pope and Duce. Catholic Students in Fascist Italy, (Nueva York, 1990) y R. Moro, La formazione della classe dirigente cattolica (1929-1937), (Bolonia, 1979). Los años que van de 1933 a 1939 son bastante desconocidos. De allí la intención de este artículo de enfocarse en esos años claves en la elaboración religiosa de los estudiantes católicos como también para entender la posición asumida por la FUCI durante la segunda Guerra mundial. Para esta última, veáse mi artículo «Catholic students at war: the Federazione Universitaria Cattolica Italiana, 1940-43», en Journal of Modern Italian Studies, 14/3 (2009), 285-304. 
ridad. Luego, el escrito examina los aportes principales de Emilio Guano, asistente eclesiástico de la federación, en particular su concepción eclesiológica. Finalmente, y en virtud de demostrar el esfuerzo de presentar una modernidad católica por parte de los estudiantes universitarios, el artículo toma elementos prestados del análisis de la literatura efectuado por los fucini de aquellos años y los engarza con los nuevos modelos de santidad presentados por la FUCI.

\section{La edificación de la personalidad religiosa}

Enfrentados con el novel desafío de las llamadas religiones politicas ${ }^{2}$, que parecían brotar como hojas de hierba entre los adoquines del continente, los estudiantes universitarios católicos de los años 1930 estaban conscientes de que una nueva clase de religiosidad tenía que ser ofrecida a las nuevas generaciones. La elevación y dignidad de los fieles laicos y la construcción de un desarrollo de la personalidad individual eran consideraciones de suma importancia. La meta principal en este ámbito era tornarse «dueño de mí mismo y de mi personalidad $\iota^{3}$. Paralelamente, dado que las religiones políticas se representaban como soluciones totales para los hombres y mujeres de la Europa de entreguerra, se estimaba necesario ofrecer a los jóvenes un catolicismo nuevo, total, como única solución para prevenir que sucumbieran a los atractivos de la sacralización de la política que se estaba llevando a cabo en el continente. Además, en la Italia de entreguerras se produjo una cierta secularización del lenguaje, imágenes y símbolos religiosos, como una forma de adaptación a las diferentes narrativas sagradas o religiones

2 Por religión politica me refiero a un tipo de religion que sacraliza una ideología, un movimiento o un régimen politico a través de la deificación de una entidad secular que es transfigurada en mito y elevado a categoría última del significado de la vida humana y de la sociedad. Hay un creciente consenso entre los historiadores en considerar al Fascismo, Nazismo y Bolchevismo como ejemplos de religiones políticas. Sobre ellas, véase, por ejemplo, H. MAIER (ed.), Totalitarianism and Political Religions. Concepts for the comparison of dictatorships, 3 vols. (Londres y Nueva York, 2004-2007); M. Burleigh, Sacred Causes. Religion and Politics from the European Dictators to Al Qaeda (Londres, 2006); R. GrifFIN (ed.), Fascism, Totalitarianism and Political Religion (Londres y Nueva York, 2005); E. Gentile, Il culto del littorio. La sacralizzazione della politica nell'Italia fascista (Roma y Bari, 2003) e IDEM, Le religioni della politica. Fra democrazie e totalitarismi (Roma y Bari, 2001).

3 S. Paronetto, Ascetica dell'uomo d'azione, (Roma, 1948), 13. Esta es una colección de los escritos de Sergio Paronetto durante la entreguerras y la 2a. Guerra Mundial. Sobre Paronetto véase M.L. Paronetto Valier - S. Paronetto, Libertà d'iniziativa e giustizia sociale (Roma, 1991). 
políticas que ocurrían en el plano político. Más aún, los fucini llevaron a cabo una modernización eclesiástica que, al menos en parte, involucró una secularización religiosa parcial, con la adopción de lenguaje, formas de acción y nuevos modelos de santidad que reflejaban parcialmente lo que Renato Moro llamó la politización de lo sagrado ${ }^{4}$. De forma similar, Fulvio de Giorgi ha trazado la omnipresencia de la metáfora militar en los discursos religiosos de la época, con énfasis en conceptos tales como guerra, soldado, batalla, milicia, heroísmo y conquista en lo que no duda en llamar un totalitarismo eclesiástico durante la Europa de entreguerras ${ }^{5}$.

A los ojos de los intelectuales de Acción Católica, lo que se necesitaba por sobre todo para poner fin a lo percibido como una crisis creciente de la civilización occidental era un catolicismo capaz de penetrar todo aspecto de la vida pública y privada, sea en los dominios políticos, sociales, económicos o culturales. Era una religiosidad que debía seguir la dirección de las necesidades de una sociedad de masas emergente, tal como era el caso de Italia en los años 1920 y 1930. El cristianismo era representado como fuerza palingenética, como revolución integral ${ }^{6}$, capaz de movilizar a las masas en un esfuerzo de sacralizarlas en una época de secularización y políticas de masas. En contraposición a la fragmentación del hombre moderno, retratado como dividido y alienado en su núcleo más íntimo, el catolicismo ofrecía una visión orgánica y unificadora, capaz de trascender los efectos deletéreos de la visión liberal de la modernidad que tan urgentemente debía ser desafiada. El deber de cada cristiano era darle un sentido religioso a todo aspecto de la vida y, al ser un catolicismo «totalitario, era evidente que el católico debía sentir todo en un sentido unitario, es decir debía traer su animus catholicus a cada uno de sus actos» ${ }^{7}$. El asistente eclesiástico Adriano Bernareggi ${ }^{8}$ deploraba la desintegración ge-

4 R. Moro, «Religion and Politics in the Time of Secularisation: The Sacralisation of Politics and the Politicisation of Religion» en Totalitarian Movements and Political Religions, 6/1 (2005) 71-86.

5 F. De Giorgi, «Linguaggi totalitari e retorica dell'intransigenza: Chiesa, metafora militare e strategie educative» en L. PAzzaglia (ed.), Chiesa, cultura e educazione in Italia tra le due guerre (Brescia, 2003), 60.

6 I. Giordani, «Valore apologetico della letteratura narrativa», Studium, n. 5 (1933).

A. Bernareggi, «La professione da un punto de vista spirituale», Studium, n. 1 (1934).

8 Adriano Bernareggi (1884-1953) fue ordenado en 1907. Entre 1923 y 1926 dictó la cátedra de Derecho Eclesiástico en la Universidad Católica de Milán. Colaboró en las revistas religiosas más importantes de su época. En 1936 fue designado obispo de Bérgamo. Adicionalmente, entre 1934 y 1953 fue asistente eclesiástico del Movimen- 
nerada por la modernidad liberal, que distinguía entre el «hombre físico, hombre ético, hombre religioso, el pensador, el profesional, el artista, el ciudadano», y clamaba por una idea central que coordinara cada aspecto de la vida y le diera una dimensión espiritual. Esta idea era, naturalmente, el catolicismo en su «concepción totalitaria, a través de la cual la religión aparece inseparable de la vida». En efecto, en tiempos de una época percibida en crisis, Bernareggi estaba confiado y optimista del rol palingenético a ser asumido por el cristianismo, ya que visualizaba una «sociedad en la cual el espíritu cristiano retomara su rol primordial» ${ }^{9}$. Estas ideas estaban en armonía con las líneas centrales del pontificado de Pío XI, quien deploraba el denominado laicismo que parecía invadir la Europa de su tiempo y que en repetidas ocasiones condenó como uno de los mayores males de su época ${ }^{10}$. Esta sensación redescubierta de optimismo, revelaba una especie de fe dentro de la crisis: la noción de que la cultura europea (producto de sus contradicciones y fallas internas) estaba siendo erosionada y corroída, dejando los campos intelectuales y espirituales vacantes, sujetos de ser sembrados de nuevas ideas. Estas ideas estaban basadas en una profunda sensación de que se le presentaba al cristianismo una oportunidad singular de transformarse nuevamente en el motor principal de la civilización occidental. Era una catolicismo arropado de un espíritu de conquista, dinámico, juvenil, incluso agresivo a veces, capaz de llenar la vacante dejada por la crisis de civilización. El catolicismo apuntó en estos años a ofrecer una «visión clara de los problemas más grandes de la vida, resueltos bajo la luz de un cristianismo totalitario» ${ }^{11}$, como la única fuerza unificadora calificada para sobreponerse a las aparentes contradicciones y confusiones entre, por ejemplo, la razón y la emoción, la ciencia y la vida, la libertad y la autoridad, y lo natural y sobrenatural. Esta visión del catolicismo fue alimentada por una concepción heroica de la vida, un cristianismo que no era vivido pasivamente o restringido a fórmulas cerradas y pasivas, sino que era experimentado apasionadamente como

to laureati, el movimiento para los graduados católicos donde entraron la mayoría de los fucini después de recibir la laurea. Sobre Bernareggi véase, por ejemplo, A. BERNARegGi, Professione, Cultura Società, (Roma, 1954) y Adriano Bernareggi Vescovo di Bergamo 1932-1953, (Bergamo, 1979).

9 A. Bernareggi, «La Moralità nella professione», Studium, n. 3-4 (1935).

10 Para el pontificado de Pío XI veáse, por ejemplo, E. Fattorini, Pio XI, Hitler e Mussolini. La solitudine di un papa (Turin, 2007); Y. Chiron, Pie XI (1857-1939) (Paris, 2004) y M. Agostino, Le Pape Pie XI et l'opinion (1922-1939) (Roma, 1991).

11 P. TAVIani, «Religione e cultura», Azione fucina, 14 Enero (1934). 
una «exaltación espiritual (...) una concepción heroica e integral de la vida católica ${ }^{12}$, capaz de develar y satisfacer a cabalidad toda facultad humana. Tal como lo expresó el influyente Giulio Bevilacqua, «la religión sólo puede reconquistar el alma moderna a través del asalto completo que reconquista todos los sentidos, todas las fuerzas del hombre (...) en orden de retornarlo gradualmente al orden divino» ${ }^{13}$.

Es claro que en una época de totalitarismos y políticas de masas, la Iglesia Católica acentuó sus rasgos como institución total y omnipresente, donde predominaba una religiosidad de militancia y movilización. Fue un proceso complejo en el cual se defendió, compitió y a veces imitó algunos de los aspectos externos de los experimentos totalitarios del continente, como la movilización de masas, las grandes concentracionse de peregrinos, el uso de distintivos visuales, entre otros. Sin embargo, sería un error conceptual hablar del catolicismo italiano de entreguerras como otro tipo de totalitarismo, dado que no comparte las mismas características que definen al totalitarismo moderno ${ }^{14}$ aún cuando, como se ha visto, muchos católicos italianos de entreguerras hablaban libremente de un totalitarismo católico.

Lo que distinguía al tipo de espiritualidad de la FUCI de las otras ramas de Acción Católica del período era su insistencia en la necesidad de un rol activo por parte de los fieles laicos. Los laicos no podían ser un cuerpo pasivo que iba a ser movilizado de manera mecánica e irreflexiva por las técnicas organizativas de la época ${ }^{15}$. Por el contrario, tenían que ser persuadidos y racionalmente convencidos de los méritos de la Verdad católica. La razón principal para este énfasis recaía precisamente en las responsabilidades y la naturaleza intelectual de la organización. Sin embargo, el propósito de la FUCI no era crear elites intelectuales restringidas, que vi-

12 I. Righettr, «Ragioni di un compito nuovo», Studium, n. 1 (1934).

13 B.G. (G. Bevilacqua), «Esperienza grande via del ritorno», Studium, n. 8-9 1939.

14 Éste es un error cometido por algunos académicos. Por ejemplo, Jone GaILLARD llega a afirmar que Acción Católica difería poco del Partido Fascista en su naturaleza totalitaria. Véase su «The Attractions of Fascism for the Church of Rome», en J. Millfull (ed.), The Attractions of Fascism. Social Psychology and Aesthetics of The Triumph of the Right', (Nueva York, Oxford y Munich, 1990), 207-214.

15 Para una comparación sucinta de las diferentes espiritualidades presentes en Acción Católica en la Italia de entreguerra, véase L. CAIMI, «Modelli educativi dell'associazionismo giovanile cattolico nel primo dopoguerra (1919-1939)», en L. Pazzaglia (ed.), Chiesa, cultura e educazione, 217-286. 
vían aparte y más allá de las vicisitudes de la vida. El fucino ideal tenía que poseer una cultura religiosa adecuada para entrar en un diálogo fructífero con las necesidades más apremiantes del día, aún aquellas aparentemente más banales. En esencia, la meta principal que todo intelectual católico debía proponerse era catolizar la vida intelectual, profesional y civil ${ }^{16}$. En la formidable tarea de retornar el mundo intelectual a las verdades de la enseñanza católica, los fucini insistieron con creciente ahínco sobre el cuidadoso respeto que debía ser entregado a todo hombre y mujer en el esfuerzo por evangelizarlos. Todo contacto en este ámbito debía ser «personal, libre, respetuoso de la autonomía de cada uno y todos» ${ }^{17}$ para alcanzar una conversión consciente y verdadera.

En esta línea de espiritualidad de la federación, el cultivo de los valores de caridad y amistad eran de suprema importancia. Franco Costa llegó incluso a afirmar que «entre las líneas dominantes de la espiritualidad de la FUCI, no hay duda de que la caridad es la dominante» ${ }^{18}$. La virtud de la caridad era presentada como una fuerza vivificante que penetraba todo aspecto de la vida católica, entregándole un sentido último y previniendo que en su aplicación se tornara excesivamente formalista, burocrática y árida. Consecuentemente la caridad era un medio para democratizar la vida religiosa, uniendo a cada miembro de la asociación, sacerdote o laico, en un sendero de perfección común como acto de amor hacia Dios, uno mismo y los hermanos compañeros. Costa no tenía dudas: «La caridad es el alma de la FUCI, es su sentido de vida, el secreto de su fecundidad» ${ }^{19}$. La caridad implicaba una renovación y regeneración en Cristo radical, una visión íntegramente nueva de la vida, un «vuelco de valores» ${ }^{20}$, dejando atrás todo instinto de egoísmo, despejando el camino a una nueva vida de desprendimiento y optimismo cristiano, un deseo ardiente de retornar

16 B.G. (G. Bevilacqua), «La qualità prima, la quantità poi», Studium, n. 3 (1939). Bevilacqua siguió dando cuenta cómo la «conquista del mundo de la inteligencia es el primer y más importante problema que el apostolado moderno debe enfrentar».

17 B.G. (G. Bevilacqua), «Note di azione pastorale per la classi colte. Pregiudizi ed illusioni», Studium, n. 4 (1939).

18 F. CostA, «La carità nella vita fucina», Ažione fucina, 8 Deciembre (1935). Sobre el rol de Costa y la importancia que le dio a la virtud de la caridad y la construcción de la personalidad interior, véase R. MORO, «Franco Costa vice-assistente della FUCI (1933-1955)», en Don Franco Costa, Per la storia di un sacerdote attivo nel laicato cattolico italiano. Studi e testimonianze, (Roma, 1992), 174ss.

19 Ibid

20 Ibid. 
al sendero de la Cruz a toda persona. ${ }^{21}$ Más aún, la caridad intensificaba la sensación de pertenencia a una comunidad espiritual, de compartir metas y bienes comunes. Además de la caridad, y cercana a ella, estaba la atención que los fucini prestaban durante esos años al tema de la amistad cristiana. Éste era otro medio para alcanzar una formación más enriquecedora de la personalidad, del carácter religioso y el cultivo de los valores de interioridad e intimidad. A través de la amistad, descrita como una total y completa entrega de sí mismo, los estudiantes perseguían una «entendimiento espiritual pleno» a través del cual «llegamos a conocer la vida íntima del amigo» con sus «inevitables miserias, sus luchas para superarlas, sus malestares, sus entusiasmos, sus conquistas». En suma, la amistad era una excelente herramienta pedagógica para enseñar cómo «los problemas de nuestro amigo son nuestros problemas, sus sufrimientos nuestros sufrimientos, sus alegrías nuestras alegrías» ${ }^{22}$. La amistad cristiana involucraba un profundo espíritu de gozo y optimismo religioso, una comunión de ideales y principios en la base de la manera de comprender la vida y actuar en ella según la FUCI. Era un sendero para «conocerse el uno al otro siempre más íntimamente (...) para así saberse constantemente

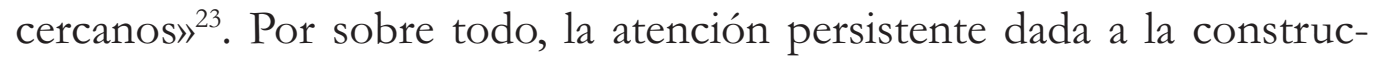
ción paciente de la personalidad y el espíritu de amistad, llevaba consigo un espíritu de sensibilidad a los problemas concretos que se enfrentaban durante la vida estudiantil, un involucramiento serio con la formación cultural, y una caridad paciente y gozosa como medio para lograr un «entendimiento recíproco» ${ }^{24}$.

En paralelo con la insistencia en los valores de la caridad y amistad, surgían otros elementos de igual importancia en los sucesos religiosos de los años 1930. Estos residían principalmente en la renovación de las ciencias religiosas propuesta por algunos en la organización, especialmente en el campo de la eclesiología. Existía por parte de estos miembros una profunda necesidad de superar la división percibida entre los mundos de la ciencia, religión y filosofía y la vida en general. Continuamente denunciaban el abismo que existía entre la producción académica en las ciencias religiosas y la práctica concreta del catolicismo cotidiano de millones de fieles. Estaban preocupados además por el escaso contacto en esos años entre las disci-

21 V. BRANCA, «La formazione fucina», Azione fucina, 1 marzo (1936).

22 G. ZAPpA, «Amicizia cristiana», Azione fucina, 19 septiembre - 3 octubre (1937).

23 F. Costareldi, «La nostra amicizia», Azione fucina, 10 enero (1937).

24 F. Costa, «Valore della vita associativa», Azione fucina, 26 marzo - 2 abril (1939). 
plinas religiosas y aquellos otros campos de estudio (o cultura profana) del mundo moderno y sus necesidades en general. Esto les resultaba principalmente urgente en el caso de Italia, donde los estudios religiosos, en alguna medida atribuibles a los impactos producidos después del modernismo, eran considerados por los fucini como especialmente caducos. Insistentemente exhortaban por una teología y cultura religiosa que fuera «menos subdesarrollada, menos provincial, más fresca y más viva, más sensible a los movimientos del espíritu humano» ${ }^{25}$. En un artículo emblemático, el asistente eclesiástico Emilio Guano ${ }^{26}$ presentó positivamente el esfuerzo del modernismo de «forzar a las personas a dedicarse a los estudios religiosos más allá de sí mismo, de tomar conciencia del mundo que los rodea» así como «un sentido de intimidad más profunda» ${ }^{27}$, rechazando al mismo tiempo las desviaciones doctrinales del modernismo. Guano proponía un contacto renovado entre la vida y la verdad cristiana, mediante una renovación profunda de las ciencias cristianas. Siguiendo los pasos de eminentes teólogos extranjeros como Guardini, Tillman y Bartmann, alabó los nuevos desarrollos en estudios religiosos que tendían a usar la investigación histórica como una herramienta auxiliar para el estudio de la teología; desarrollos que servían al fin último de presentar investigación y estudios teológicos «accesibles a los hombres que viven hoy» ${ }^{28}$, en un esfuerzo de entregar de forma viva y vital el mensaje cristiano a la sociedad contemporánea. La doc-

25 E. Guano, «Verità e vita», Studium, n. 7-8 (1935).

26 Emilio Guano (1900-1970), fue ordenado en 1922. En 1926 asumió como el asistente eclesiástico del círculo masculino de la FUCI en su nativa Génova. Al mismo tiempo, enseñó en el Seminario de Génova, donde dictó las cátedras de Historia Eclesiástica, Sagradas Escrituras y Patrología. En 1935 fue designado como Viceasistente Eclesiástico Nacional de la FUCI. En 1943 fue nominado como vice-asistente eclesiástico nacional del Movimento laureati, y en Julio de ese año participó en la asamblea en Camaldoli, de donde emergería el famoso documento Codice di Camaldoli. Después de la Segunda Guerra Mundial, jugaría un rol preponderante en la reconstitución de la Pax Romana, la organización internacional de los intelectuales Católicos. En 1962 fue designado por Juan XXIII como obispo de Livorno. Durante el Concilio Vaticano Segundo (1962-1965) participó en la elaboración del documento Gaudium et spes, instancia en la cual contribuyó con su vasto conocimiento en eclesiología. Sobre Emilio Guano véase, por ejemplo, L. ROLANDI, Emilio Guano. Religione e cultura nella Chiesa italiana del Novecento (Catanzaro, 2001); M.L. Paronetto Valier (ed.), Emilio Guano. Conscienza/Libertà/Responsabilità, (Roma, 1998); A. Ablond, A. Ballestrero y M. Marcocchi, Don Guano. Vescovo Teologo, (Roma, 1992) y E. Guano, Uomo della Parola, (Roma, 1977).

27 E. Guano, «Verità e vita», Studium, n. 7-8 (1935).

28 Ibid. 
trina católica, entendida de esta manera, emergía como una fuerza capaz de organizar, vivificar y elevar al mundo moderno. En contraposición, Guano tenía duras palabras para lo que consideraba era la naturaleza de los estudios religiosos en la Italia contemporánea: «La orientación de nuestros estudios religiosos está demasiado obsoleta como problema, método y sensibilidad. Demasiado poco sabe nuestra cultura religiosa acerca de lo que es la cultura, mentalidad, ansiedades y necesidad del mundo civil de este, nuestro siglo

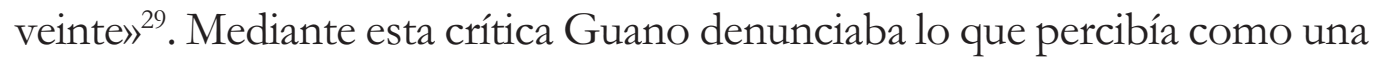
cultura religiosa satisfecha con la presentación de una fórmula abstracta: una cultura autocontenida y fría, inserta confortablemente en esquemas rígidos, sin esfuerzo alguno de dialogar animadamente con el dinámico mundo moderno. En este sentido, la FUCI (y Emilio Guano en particular) hizo un esfuerzo consciente y valioso con el fin de producir estudios teológicos italianos menos provincianos. En 1937, por ejemplo, el círculo de Bologna de la FUCI había invitado a Romano Guardini para hacer una ponencia en su sede, aunque este intento finalmente fallaría $a^{30}$. La FUCI logró presentar a la audiencia italiana, en algunos casos por primera vez, las ideas foráneas más recientes en estudios religiosos y teológicos, especialmente el trabajo llevado a cabo en Alemania y Francia. La asociación se suscribió a las revistas religiosas foráneas más importantes de su tiempo ${ }^{31}$ y algunos de sus líderes, como Emilio Guano, viajaban frecuentemente al extranjero para seguir en contacto con los últimos desarrollos del campo de estudio. ${ }^{32}$

29 Ibid.

30 Véase el Archivio della Presidenza della FUCI, Bologna. Emilio Guano alabó a Guardini «como una de las figuras más representativas de la necesidad de construir puentes entre la verdad y la vida». Véase E.G. «Segnalazioni», Studium, n-7-8 (1935). Romano Guardini (1885-1968), hijo de padres italianos, vivió la mayor parte de su vida en Alemania. Es probablemente uno de los teólogos más creativos del siglo veinte, quien anticipó el compromiso del Vaticano II de leer «el signo de los tiempos». Teólogos tan conocidos como Hans Urs von Balthasar, Karl Rahner y el actual papa, Benedicto XVI, han reconocido su deuda intelectual y religiosa con él. Sobre la importancia de Romano Guardini véase, por ejemplo, R.A. Krieg, Romano Guardini. A Precursor of Vatican II, (Indiana, 2001) y A. LóPEZ QuinTÁs, Romano Guardini, maestro de vida, (Madrid, 1998).

31 Por ejemplo: La Vie Intellectuelle, La Vie Catholique, Revue Apologetique, Etudes Carmelataines, Documentation Catholique, La Revue Hebdomadaire, Stimmen der Zeit, Theologie und Glaube, Catholic Times, entre muchas otras. Véase Archivio del Movimento laureati, b.1943 n. 2-3.

32 En 1935, Guano visitó Suiza, Austria y Alemania y en 1937 Francia. Véase la carta de Guano a Righetti, 8 Agosto 1937, en Archivio del Movimento laureati, b.1934 n. 2-3. 
La FUCI mostró confianza en el potencial del mensaje cristiano de alcanzar a toda la humanidad y no sólo a unos pocos fieles escogidos y delimitados. Esto requería enfrentar el desafío de ofrecer un catolicismo constructivo, que tomara nota que «allí, más allá de nosotros [...] existen en el corazón humano aspiraciones ardientes y vívidas, y no sólo seres que son inmóviles y que yacen paralizados por su egoísmo y bestialidad» ${ }^{33}$. Aunque constituiría un error conceptual hablar de un espíritu ecuménico verdadero en la FUCI de los años 1930, este deseo confiado y optimista de alcanzar a aquellos ajenos al catolicismo reflejaba un sentido y compromiso de entrar en diálogo con los hombres y mujeres contemporáneos, en un esfuerzo de construir una modernidad alternativa católica, una modernidad que rescatara los elementos dinámicos de la cultura del día, persiguiendo al mismo tiempo anclarla en los principios inmutables del catolicismo. Era una espiritualidad enraizada en un catolicismo vivido, que guiaba más por el ejemplo que por predicar abstracta y moralistamente la piedad. Esta era una actitud que percibía la piedad como un elemento experiencial de vida, y no como algo «formalista, externo o sentimental» ${ }^{34}$. Por lo tanto era necesario liberar el mensaje religioso de cualquier tipo de «intelectualismo árido que menosprecia el sí mismo» ${ }^{35}$. De hecho, los intelectuales católicos italianos trataron de cruzar la división percibida entre teoría y práctica, representándolas no en oposición sino que mutua y necesariamente reafirmantes, donde la práctica no era otra cosa que la traducción de ideas y teorías ${ }^{36}$. Similarmente, Fausto Montanari remarcó que el catolicismo contemporáneo tenía que ser dinámico y activo, en suma vital y en una relación constante con el mundo externo. Así, advirtió del «peligro de un misticismo abstracto y ascético, a través del cual nos desapegamos y alejamos del mundo, como si fuéramos individuos aislados y no miembros de Cristo destinados a traer la vida de Cristo a nuestros tiempos $\aleph^{37}$. Un catolicismo fecundo tenía que ser dinámico, de constante novedad, una elección radical donde no era permitdo el retorno. Es más,

33 «Per un Cristianesimo costruttivo», Ažione fucina, 26 mayo (1935).

34 G. GetTo, «L'anima del apostolato», Azione fucina, 28 enero (1936).

35 E. Guano, «Teoria e pratica», Azione fucina, 13 junio (1937).

36 Ibid. Véase además Ana Maria Ferrero, «Intellettualismo e vita cristiana», Ažione fucina, 4 julio (1937), donde expresa su «disgusto por la teoría abstracta que no produce acción» y en contra de aquellos que «se encierran en un mundo de ideas que no son fuerza».

37 F. Montanari, «Gesù Cristo e il novecento», Studium, n. 5 (1938). 
el verdadero católico era más reconocible «afuera que dentro del templo», «en sus asuntos mundanos más que en sus rezos», más en «sus placeres que sus ayunos» $\rangle^{38}$.

La FUCI insistía en un tipo de existencia cristiana optimista y gozosa, una vida que no coartara todo instinto y vitalidad. Los estudiantes rechazaban enérgicamente cualquier noción del catolicismo que estuviera limitada a una «mera mortificación» ${ }^{39}$. En su insistencia sobre el gozo y el optimismo, los fucini frecuentemente hablaban del alma sonriente de la FUCI y cómo ésta había erigido al gozo como norma fundamental de su existen$\mathrm{cia}^{40}$. Además, el gozo implicaba un sentido de asombro y sorpresa ante las realidades intramundanas y una atención especial sobre los elementos dinámicos, subjetivos, psicológicos, éticos e individuales de la experiencia religiosa. Era el elemento personal para ser rescatado de la religión o la fenomenología religiosa: la edificación de la personalidad y la interioridad, el cristianismo como una forma de perfección moral que liberaba el verdadero potencial del hombre ${ }^{41}$. Al interesarse en los elementos subjetivos de la vida religiosa, se prestó mucha atención a la educación de los sentimientos y emociones, como elementos integrales de la vida católica. Era una manera de retirar el semblante amenazante de un cristianismo árido y racionalista, considerándose una excelente herramienta pedagógica para la formación de un carácter varonil y robusto. ${ }^{42}$ En consonancia con las tendencias más recientes en los estudios litúrgicos de esos años ${ }^{43}$, especialmente provenientes de Francia y Alemania, los fucini rechazaban el excesivo formalismo y exteriorismo de muchas manifestaciones litúrgicas. Para estos intelectuales católicos, el verdadero espíritu y mensaje de la liturgia no estaba contenido en sus ritos, estéticas, ceremonias o en el conocimiento histórico de los orígenes de la liturgia. Para que fuera una experiencia fructífera, los fieles tenían que «vivir la liturgia» ${ }^{44}$ en una par-

38 Miles (G. Bevilacqua), «L’uomo nuovo», Studium, n. 4 (1934).

39 F. Costa, «Esseri lieti», Azione fucina, 21 noviembre (1937).

40 Ibid.

41 Véase, por sobre todo, G.B. Montinı, «L'elemento personale nella religione», Ažione fucina, abril (1934).

42 C. RighinI, «L'educazione degli affetti», Azione fucina, 8 agosto (1937).

43 Para una historia del movimiento litúrgico de esos años, véase el excelente estudio realizado por M. Paiano, Liturgia e Società del Novecento. Percorsi del movimento liturgico di fronte ai processi di secolarizzazione, (Roma, 2000).

44 E. Rossi, «Il valore formativo della liturgia», Azrione fucina, 12 julio (1936). 
ticipación consciente en el rezo colectivo y oficial de la Iglesia. La liturgia evocaba una «nostalgia de Dios» y era «por sobre todo, una educación de la personalidad», una «formación integral del hombre» ${ }^{45}$; representaba la parte más vital y cotidiana de la existencia cristiana, el medio por el cual los fieles participaban en la vida de la Iglesia o del Cuerpo Místico de Cristo. Se esperaba que los fieles laicos no participaran pasivamente en las celebraciones litúrgicas, sino que con una «participación activa e inteli-

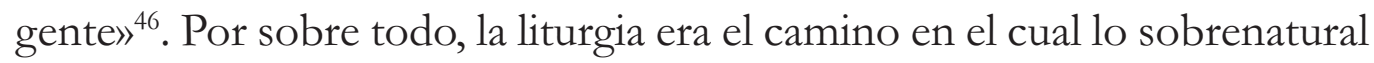
se manifestaba y actuaba sobre los hombres y mujeres, formando su conciencia y el sentido de pertenencia a una misma comunidad espiritual.

\section{La contribución de Emilio Guano}

Emilio Guano, sacerdote genovés, fue sin lugar a dudas una de las voces más originales e influyentes en los estudios religiosos de la Italia de entreguerra, particularmente en el campo de la eclesiología. Ya hemos visto cómo en su influyente artículo titulado Verità e vita, el asistente eclesiástico proponía una cultura religiosa viva, capaz de ofrecer respuestas a las necesidades más apremiantes del día rescatando algunas de las fuerzas motoras del modernismo, rechazando al mismo tiempo sus desviaciones doctrinales. Por otro lado se ha hecho mención del esfuerzo de Guano de introducir las más recientes ideas teológicas provenientes del extranjero, especialmente de Francia y Alemania ${ }^{47}$. Durante estos años, Alemania estaba experimentando un renacimiento animado y fecundo de la vida católica en general. Este renacimiento tuvo sus centros en la Abadía Benedictina de Maria Laach liderada por Ildefons Herwegen, la Facultad de Teología Católica de la Universidad de Tubingen y la Akademiker Verband. Algunos de los principales intelectuales de este renacimiento fueron Romano Guardini, Fritz Tilmann y Karl Adam ${ }^{48}$. Todos estos autores, y respectivas instituciones, eran conocidos a cabalidad por Guano, tanto a través de la lectura como de sus frecuentes viajes a esa nación. Pero su atención y sus intereses teológicos no estaban limitados a los autores católicos. Exhortaba constantemente a los fucini a que «abrieran

45 Ibid.

46 G. Moglia, «Rassegne», Studium, n. 2 (1935).

47 Se debe hacer mención del excelente conocimiento y manejo del alemán por parte de Guano.

48 R.A. KrIEG, Catholic Theologians in Nazi Germany, (Nueva York y Londres, 2004) y W. Spael, La Germania cattolica nel XX secolo (1890-1945), (Roma, 1974). 
los horizontes hacia hombres y movimientos que no fueran católicos o cristianos» ${ }^{49}$. También mostró interés en las voces más distinguidas del protestantismo liberal, como es el caso de Karl Barth y su movimiento de renovación, al cual alabó como «embarcado en un sendero exquisitamente sobrenatural $\rangle^{50}$. Similarmente, a pesar del clima intelectual dominante y a veces sofocante del neotomismo, Guano animó a los intelectuales católicos italianos a que fueran más allá de las enseñanzas en filosofía de Tomás de Aquino, en un esfuerzo por rescatar las corrientes filosóficas más actuales del día. En este sentido, fue indicativo del intento del asistente eclesiástico de tender la mano a los hombres y mujeres modernos el que loara algunos aspectos de filósofos modernos como Bergson y Heidegger, como ejemplos de cómo «la filosofía busca tornarse en algo más humano» ${ }^{51}$. Su posición con respecto al tema de los judíos fue igualmente sorprendente para la época en que vivió. En tiempos en que el antisemitismo católico permanecía robusto en muchos círculos ${ }^{52}$, el sacerdote genovés valiente y vehementemente rechazaba cualquier tipo de noción de antisemitismo o antijudaísmo. En un artículo publicado en mayo de 1937, Emilio Guano clamaba apasionadamente por «la necesidad de acercarnos a esta raza a la que le debemos tanto: le debemos a Jesús. Necesitamos arrancar cualquier tipo de antisemitismo en nuestros corazones, aún antes que en la vida pública» ${ }^{53}$.

Guano estaba firmemente convencido de que cada era tenía su propia espiritualidad, su propia manera de comprender la relación entre el sí mismo y lo absoluto y trascendental. De acuerdo con el asistente eclesiástico, la espiritualidad dominante de su época era la vocación de santificar todo lo que fuera humano. Estaba convencido de que la verdadera santidad no era «el deber o privilegio de unos pocos, sino que la vocación de todo

49 E. GuANO, «Spiritualità», Studium, n. 7-8 1935.

50 Ibid.

51 E. GuAnO, «Verità e vita», Studium, n. 7-8 1935.

52 La bibliografía sobre la historia del anti-semitismo católico es muy extensa. Véase, por ejemplo, F.J. Coppa, The Papacy, the Jews, and the Holocaust, (Washington D.C., 2008); R. Moro, La Chiesa e lo sterminio degli ebrei, (Bologna, 2002) y D.I. KerTzer, The Popes against the Jews, The Vatican's role in the rise of modern anti-Semitism, (Nueva York, 2001).

53 E. Guano, «I Giudei e Gesù», Studium, n. 5 1937. Un año más tarde. el 6 de septiembre de 1938 sería el propio Pío XI quien denunciaría enérgica y públicamente el antisemitismo al declararlo inadmisible y sosteniendo que «espiritualmente somos todos semitas». Veáse E. Fattorini, Pio XI, 181. 
cristiano [...] fuese cual fuese su condición de vida» ${ }^{54}$. En su empeño de traer a todo hombre y mujer al sendero de la santidad, Guano puso especial énfasis en la figura del sacerdote como el pastor que lideraría a la humanidad hacia Dios. Se necesitaba un sacerdote de tipo moderno para cumplir su misión, en sintonía con el mundo y sus necesidades, capaz de presentar el dogma cristiano a los fieles de una «manera moderna, viva, menos defensiva y más constructiva» ${ }^{55}$. Similarmente, la liturgia y Acción Católica eran herramientas para la santificación del hombre.

En suma, el núcleo del pensamiento religioso de Guano era, nuevamente, la centralidad de los laicos y la edificación de una vida interna. El asistente eclesiástico insistía en que la teología no era reservorio de un puñado de sacerdotes o académicos, sino que era deber de cada fiel de conocerla y practicarla, una teología entendida como una fe viva que proveía la base para aquello en lo cual uno creía. Guano jamás cedió en cuanto a este aspecto: «No una teología para los laicos en el sentido de que existe una teología para el clero y otra para los laicos. No, la teología, la única teología, ciencia de la Revelación, también está dirigida a los laicos, porque simplemente está hecha para cada cristiano» ${ }^{56}$. El asistente eclesiástico insistía en la necesidad de ir más allá del simple apologizar y dar un mayor contenido histórico a la fe, siempre con el fin de presentar más viva y actual la vida de los fieles: «el pensamiento Cristiano no puede vivir encapsulado en sí mismo [...] sino que está hecho para comunicarse al mundo y salvarlo. Por ende, debe ser inteligible al mundo y a los hombres de su tiempo; es una necesidad de ir y responder a la sensibilidad de los tiempos $\gg{ }^{57}$. Por lo tanto, para Guano renovar el pensamiento teológico era de suma importancia, presentándolo más accesible y claro a los laicos, removiendo todos los elementos que pudieran hacerlo críptico o esotérico y por lo tanto, un lenguaje muerto a oídos de los fieles.

Es en el campo de la eclesiología donde Guano habría de dejar su legado más duradero. La eclesiología predominante de la Italia de la época estaba vigorosamente enraizada en el modelo Tridentino. Éste estaba basado en un apuntalamiento más bien tajante de la Iglesia como sociedad perfecta autocontenida, enfocada primordialmente en sus dimensiones ju-

\footnotetext{
54 E. Guano, «Spiritualità», Studium, n. 11 (1935).

55 E. Guano, «Attorno a Cristo», Studium, n. 2 (1936).

56 E. GuAno, «Teologia per i laici», Studium, n. 11-12 (1938).

57 E. Guano, «Indirizzi storici», Studium, n. 21937.
} 
rídicas y jerárquicas ${ }^{58}$. Sin embargo, durante los años 1930, Emilio Guano y otros en la FUCI entraron en un animado debate, introduciendo las corrientes eclesiológicas y litúrgicas más actuales, predominantemente desde Francia y Alemania, tal como ha sido afirmado ${ }^{59}$. En 1936, Emilio Guano publicó el volumen La Chiesa, ampliamente distribuido, el cual consistía en una colección de las lecciones que había impartido en el año académico 1934-5 en Génova al círculo de la FUCI de esa ciudad. Al centro de la interpretación de la Iglesia por parte de Guano estaba la noción de la institución esencialmente como el Cuerpo Místico de Cristo ${ }^{60}$, el lugar donde se torna real la comunión entre hombres y Dios. Significativamente, y para subrayar la comunión entre hombres y Dios, utilizó la imagen de la familia para referirse a la Iglesia ${ }^{61}$. La Iglesia presentada por Guano era además una realidad dinámica, abierta, un organismo vivo, en continua fermentación y renovación. El sacerdote genovés hablaba de la Iglesia como un «gran sitio de edificación, que siempre tiene algo que agregar a su construcción $»^{62}$. Por ende, de acuerdo con esta aproximación la Iglesia no era representada como una realidad estática sobre el curso de la historia ni como una milicia progresiva e inmutablemente avanzando a través de este valle de lágrimas, indiferente a las realidades socioculturales específicas de la era.

Para Guano, la Iglesia era la continuación de Cristo. De hecho, según Guano «la Iglesia es el Cristo vivo entre la humanidad» ${ }^{63}$. De igual importancia era el reconocimiento de un sacerdocio laico otorgado por el sacramento del bautismo. Este punto, como otros ya mencionados, era un importante alejamiento de gran parte de las enseñanzas teológicas de aquellos años. En la concepción del asistente eclesiástico, los laicos no eran representados como un cuerpo indiferenciado e indiferente, sino

58 Aproximaciones generales de buena calidad sobre la eclesiología durante el pontificado de Pío XI pueden ser encontradas en M. Agostino, Le Pape Pie XI et l'opinion (1922-1939), (Roma, 1991), 82ff y G. Martina, «L'Ecclesiologia prevalente nel pontificato di Pio XI», en A. Monticone (ed.), Cattolici e fascisti in Umbria (1922-1945), (Bologna, 1978), 221-244.

59 Autores tales como M.D. Chenu, H. Clerissac, Y. Congar, R. Guardini y C. Marmion.

${ }^{60}$ La noción de la Iglesia como Cuerpo Místico de Cristo había sido avanzada tímidamente durante el primer Concilio Vaticano, pero no había sido recibida favorablemente. Sólo sería durante los años 1920 que adquiriría un nuevo impulso.

61 E. Gunno, La Chiesa (appunti di lezioni), (Roma, 1936), 24-25.

62 Ibid. 138.

63 E. Guano, La teologia nella vita sacerdotale, (Brescia, 1939), 141. 
que como una realidad dinámica que podía y debía ser involucrada activamente en las preguntas religiosas y culturales más importantes de la época. Los fieles eran capaces de contribuir al cumplimiento y logro de la comunidad religiosa ${ }^{64}$. La teología de Guano no implicaba un intento de podar las estructuras jerárquicas y monárquicas de la Iglesia ni, siquiera de la manera más tentativa, cuestionar el dogma de la infalibilidad papal. Sin embargo, el afloramiento y elaboración de la centralidad, creatividad y dignidad del sujeto religioso individual, considerado «no como un portador pasivo sino que activo colaborador del Señon ${ }^{65}$ fue quizás el legado espiritual más duradero de Emilio Guano y de los intelectuales católicos de la época en general.

En concordancia con las perspectivas de Guano, estaba la valerosa y crucial publicación de un artículo por el teólogo belga Yves Congar, quien posteriormente alcanzaría renombre. Este artículo fue publicado en tres números sucesivos de Azione fucina ${ }^{66}$ durante 1935, y había aparecido previamente en el tremendamente influyente periódico francés, La Vie Intellectuelle. La contribución de Congar fue una irrecusable acusación del modelo de Iglesia basado en anatemas y actitudes mentales defensivas que habían traído un lamentable «hiatus entre la fe y la vida $»^{67}$, y que apuntaba al corazón del modelo Tridentino: «Desde la ruptura de la Reforma la Iglesia vive bajo un verdadero estado de sitio. Después de una crisis [...] son introducidas medidas policiales y de seguridad: de esta manera, en la Iglesia, son subyugadas las manifestaciones originales de pensamiento [...] Sin duda, las iniciativas son obstaculizadas; por sobre todo, los laicos no osan involucrarse en acciones más audaces, ni expresar ideas que sean más personales $)^{68}$. Dada esta situación, el teólogo se encontraba muy pesimista acerca de la Iglesia institucional después de la crisis modernista y las acciones llevadas a cabo por Pío X, que habían resultado en un «conformismo estrecho que dominaba la enseñanza eclesiástica $\rangle^{69}$ y que había producido un alejamiento fundamental del mundo moderno: «Una parte

${ }^{64}$ E. Guano, La Chiesa, 99-100.

65 Ibid.

${ }_{66}$ El artículo fue publicado con el significativo título de «Il mondo moderno e la fede. Cause dell'incredulità contemporanea» en los números de 20 octubre, 3 noviembre $\mathrm{y}$ 17 noviembre (1935).

67 Ibid, 20 octubre (1935).

68 Ibid, 17 noviembre (1935).

69 Ibid. 
inmensa de la actividad humana, una generación completa de la humanidad, de carne humana - de la vida moderna con ciencia, con sus miserias y grandezas- ha sido deprivada de la Encarnación del Verbo» ${ }^{70}$. El catolicismo no podía ser un grupo aparte ni una secta ${ }^{71}$ si quería abrazar la fluidez y complejidad de la vida moderna. Congar finalizó el artículo exhortando a la Iglesia a incorporar en su seno todo aquello que fuera humano, implícitamente desafiando los grandilocuentes planes hierocráticos de Pío XI: «Políticas de presencia; no una política de prestigio al servicio de algún tipo de imperialismo eclesiástico» ${ }^{72}$.

\section{Literatura y nuevos modelos de santidad}

Las artes, especialmente la literatura, eran vistas por los fucini como agentes privilegiados para un nuevo y moderno orden espiritual. El arte por el arte fue firmemente rechazado por su desapego con la realidad concreta y su supuesto substrato burgués ${ }^{73}$. En el que ahora es un muy famoso artículo, el escritor católico Carlo Bo sintetizó convincentemente el nuevo ímpetu en dirección a la realidad que la literatura tenía que seguir en la Italia de entreguerra, si es que iba a ser una expresión justa y digna de la modernidad. La verdadera literatura no podía ser considerada como una evasión o un mero pasatiempo para la pura gratificación de la imaginación. Tenía que ser un compromiso con la vida, quizás el más crucial en los tiempos modernos para «nuestro autoconocimiento y la vida de nuestra conciencia» y por lo tanto «no podía haber oposición entre literatura y vida» ya que ambos eran esencialmente «instrumentos de búsqueda del sí mismo y por lo tanto, de la verdad ${ }^{74}$. El texto escrito tenía que captar el dinamismo de la vida moderna y la literatura moderna ${ }^{75}$ era alabada por su ambición de palpar la «esencialidad de las cosas». La literatura tenía que ser concebida como un medio para «vivir nuestros tiempos sin mortificarlos

70 Ibid.

71 Ibid, 20 octubre (1935).

72 Ibid. 17 noviembre (1935).

73 «Rassegne», Aquione fucina, 29 enero (1933).

74 C. Bo, «Letteratura come vita», Il Frontespizio, septiembre (1938).

75 Para aproximaciones generales de buena calidad a la literatura de la Italia Facista, véase por ejemplo, G. FERroni, Storia e testi della letteratura italiana. Guerre e fascismo (1920-1945), (Città di Castello, 2004); G. MANACORDA, Storia della letteratura contemporanea 1900-1940, (Roma, 1999) y G. LuTI, La letteratura del ventennio fascista, (Florencia, 1972). 
y sintiendo su avidez de construir y elevar [...] y su anhelo por un orden nuevo» ${ }^{76}$. Muchos intelectuales católicos siguieron los grandes desarrollos de la literatura italiana, particularmente el desplazamiento a la novela y al realismo como los medios de representación preferidos, cercanamente unidos a las visiones de unidad nacional ${ }^{77}$. Sin embargo, no proponían una literatura realista que presentara la realidad de manera meramente fotográfica y pasiva. En consonancia con el «realismo espiritual» propuesto por el fascismo, se suscribían a un realismo que transformara y purificara de sus degeneraciones a la realidad. El nuevo realismo debía «reinventar nuestro héroes»y develar las «raíces más profundas» de la vida ${ }^{78}$.

Un buen ejemplo de este realismo terapéutico es visible en el interés mostrado por la literatura y cultura de los Estados Unidos ${ }^{79}$. Existía la tendencia entre católicos de identificar el liberalismo económico con el capitalismo en su globalidad y a los Estados Unidos como la cuna y más puro ejemplo de la sociedad capitalista moderna. El capitalismo había sido sujeto de una significativa campaña de demonización en los años precedentes. El contexto de los años 1920 y 1930 después del desplome financiero de 1929 en Nueva York, trajo sin lugar a dudas una radicalización de este proceso de desprestigio. Para muchos, 1929 pasó a ser percibido como un año de inflexión crucial, señalado por los Pactos Lateranos y la supuesta derrota histórica del capitalismo ${ }^{80}$. Se le asignaba al capitalismo la culpa de las desastrosas realidades económicas y sociales en las cuales estaban sumidos millones de ciudadanos europeos; de la destrucción de los valores espirituales y morales; y del culto al dinero y las apariencias. En muchos aspectos, el capitalismo se tornó en la encarnación de esa moder-

76 F. Brocchieri, «Tempo di costruire», Azqione fucina, 12 marzo (1933).

77 Con respecto a la tendencia realista, véase, R. BEN-GHiAT, Fascist Modernities. Italy 1922-1945, (Berkeley y Londres, 2001), 46-69; G. LANGELLA, Il secolo delle riviste, (Milán, 1982) y C. De Michelis, Alle origine del neorealismo, (Cosenza, 1980).

78 E. CabiancA, «Ha ragione Bontempelli», Studium, n. 7-8 (1933).

79 Para entender las actitudes Italianas hacia América del período en estudio, véanse por ejemplo los capítulos relevantes en V. DE GrAZIA, Irresistible Empire. America's advance through 20th century Europe, (Cambridge Mass., y Londres, 2005); D. Sarasella, Cattolicesimo Italiano e sfida Americana, (Brescia, 2001); M. BEYNER, L'image de l'Amerique dans la culture italienne de l'entre deux guerres, 3 vols., (Aix-en-Provence, 1990) y E. GentiLe, «Impending Modernity: Fascism and the ambivalent image of the United States», Journal of Contemporary History, 28/1 (1993), 7-29.

80 P.A. VermeErXCH, «L'attualità dell'enciclica», Studium, n. 5-6 (1932), en el cual el autor proclama triunfante que se había «derrocado a la economía liberal para siempre». 
nidad que con tanta urgencia tenía que ser enfrentada y convertida. Predeciblemente, se condenó sumariamente a la mentalidad estadounidense como una seudocivilización donde existía la «convicción de que el éxito era el único criterio digno de atención», donde «el dinero tiende a ser la única medida de inteligencia y virtud; donde la simplicidad reduce la vida a la exterioridad ${ }^{81}$. Más aún, se representaba a los Estados Unidos como la tan detestada civilización máquina por esencia, un lugar donde una «gran riqueza es la causa de la miseria más oscura, y la abundancia de productos mata de hambre a las personas; esta civilización tan avanzada desde el punto de vista tecnológico, empuja a una multitud de hombres a los límites de la barbarie, la desesperación y la delincuencia» ${ }^{82}$. En suma, los Estados Unidos eran un lugar donde «Dios era extrañamente ignorado» ${ }^{83}$. Sin embargo, y nuevamente a pesar de la decadencia y destrucción percibida, algunos católicos eran capaces de ver y acoger las miserias, las debilidades y desesperanzas y, desde su interior, aislar momentos de belleza y resplandor humano en una suerte de modernidad Baudeleriana, que rescataba los aspectos heroicos y a veces escondidos de la vida moderna ${ }^{84}$. Un buen ejemplo son las reacciones de un periodista católico a las descripciones de Nueva York ofrecidas por el escritor John Dos Passos en su novelas. La ciudad es presentada como dinámica, esquizofrénica, viviendo en una borrachera de los sentidos sin fin aparente, donde las personas «viven un día de reposo y diez de miseria» ${ }^{85}$. Aún así, entre la anormalidad y la corrupción, el periodista se enfocó en Jimmy Herf, uno de los personajes de Dos Passos que, a pesar de todo, conservaba una lealtad poética a su madre patria y (cual Don Quijote moderno) desde la grandeza anónima de su espíritu, cargó sobre sí como un Jesús urbano «todo el sufrimiento y tristeza de esta ciudad inmensa» ${ }^{86}$. Un acto de redención que penetraba lo efímero de la vida urbana y avizoraba su potencial eterno. El columnista prosiguió decifrando el mensaje encerrado en la obra de Sinclair Lewis,

81 E.M., «Lettere dall'estero. Le deficienze della mentalità americana», Studium, n. 2 (1931). Al final, el autor advierte con solemnidad contra males amenazantes como el mostrar filmes en inglés a audiencias extranjeras.

82 A. Zamboldi, «Furore, de John Steinbeck», Ažione fucina, 23 junio (1940).

83 ABI, «Quattro romanzi», Studium, n. 6 (1940).

84 Para la concepción Baudeleriana de la modernidad, véase el fino análisis de M. BERMAN en su All that is solid melts into air. The experience of modernity, (Londres y Nueva York, 1983), 131-171.

85 O.S., «Due libri americani». Azione fucina, 20 abril (1933).

86 Ibid. 
otro escritor representativo de la época, en uno de sus cuentos sobre un mecánico y la hija de una pareja burguesa de buen pasar económico. Su mayor contribución estaba en el retrato del esnobismo y superficialidades de la «burguesía americana obesa ${ }^{87}$ que transformaba la vida en artificial, conformista y afeminada; y el acento puesto en la añoranza del retornar a una naturaleza mágica donde el hombre pudiera aflorar nuevamente. Dos Passos y Lewis hablaban directo al corazón de la juventud contemporánea con su «crítica de los valores anticuados y en su búsqueda de nuevos postulados para la vida individual y colectiva» ${ }^{88}$, es decir, una vida nueva que dejara de lado lo espurio y reclamara un rol central para el elemento esencial de la modernidad: el desarrollo del sí mismo y su cruzada en aras de la autenticidad.

Es bajo esta luz que uno debiera considerar las modificaciones significativas en las creencias, conductas y formas de santidad religiosas que se llevaron a cabo en la Italia de entreguerra. Los intelectuales católicos lucharon por una vida religiosa que en respuesta al ánimus de aquellos tiempos, fuera al mismo tiempo dinámica, vital y juvenil. El núcleo de estos desarrollos era la primacía asignada al ideal moderno del desarrollo del ser, el ímpetu de consolidar la dignidad de la conciencia religiosa individual, contenida en una concepción nueva de la Iglesia como comunidad. Más aún, durante los años 1930, los católicos expresaban una fuerte aversión a la superficialidad religiosa y las convenciones sociales pueriles de ciertas conductas religiosas. Menospreciaban energéticamente los intentos percibidos de reducir la religión a un código moral, un manual burgués de modales de comportamiento urbano que excluía «todo aquello que es bello y robusto fuera de él» ${ }^{89}$. En suma, hicieron campaña contra una religión pechoña e intolerante que giraba alrededor de la seguridad y comodidad de hábitos adquiridos, que dejaba al catolicismo como «formal y no sustancial, aparente y no efectivo», que evitaba las intrincancias y tormentos de la vida heroica, reduciéndolo a un «Fariseísmo insufrible» ${ }^{90}$.

Sanford Schwartz ha argumentado que al centro del intento de regeneración de la cultura por parte del modernismo, existía la creencia de que la civilización había cubierto lo que era más vital y esencial para la existencia

87 Ibid.

88 Ibid.

89 F. Montanari, «Umanesimo cristiano», Azione fucina, 5 marzo (1933).

90 G. G: «I giovani e il cattolicismo», Azione fucina, 9 noviembre (1933). 
humana, por ende, sembrando y enraizando el anhelo de develar y liberar las fuerzas primordiales y originarias del hombre ${ }^{91}$. Aunque su trabajo trata principalmente con el mundo estético, puede ser útil aplicarlo a los católicos de entreguerra en su búsqueda de una experiencia religiosa auténtica, espontánea y catártica, cuyo fin principal era construir la personalidad religiosa individual. La fe y la vida no debían ser consideradas estados de la mente dados por hecho, que de alguna manera mecánica e inconciente empujaban al hombre a lo largo de los años, sino que como lucha y constante desafío en la conquista de la propia intimidad. Consecuentemente, la juventud era un poderoso símbolo de fortaleza, pureza y fuerza moral, y se representaba a los jóvenes como grupos avant-garde, «constructores tenaces y voluntariosos que ven más allá de los horizontes estrechos de hombres panzones y buscadores de estátus $\rangle^{92}$. La experiencia religiosa verdadera desinhibía «el goce interior de los hombres», un goce que era el «efecto liberador de la posesión de la Verdad» ${ }^{33}$. Si la religión iba a ser fecunda, tenía que ser algo experienciado y, por lo tanto, tenía que acoger las paradojas y contradicciones de la vida moderna. Se necesitaba una actitud religiosa nueva para hacer frente a la naturaleza fluida de la sociedad contemporánea y poder florecer en ella; una mezcla de espontaneidad y trascendencia del dogma católico para la cual la juventud estaba particularmente preparada a través de su «maravillosa aleación de exhuberancia juvenil y seriedad moral $\rangle^{94}$. Esta tendencia puede ser trazada en la atención considerable que se le brindó a Giovanni Papini, el converso más célebre en la Italia de entreguerra. En 1921 había publicado su personalísima Storia di Cristo, sin duda el libro religioso más leído de su tiempo (sólo en en ese año vendió más de 40 mil copias ${ }^{95}$ ). La caracterísica más llamativa del libro es la escasa atención que le brinda a las dimensiones institucionales de la Iglesia, prefiriendo entregar un retrato del catolicismo como un encuentro personal con Cristo, como un viaje, una aventura con altos y bajos, tormentos y sorpresas que llevan al descubrimiento de la naturaleza real y heroica del hombre. Aludiendo a la intención moderna de su trabajo, Papini escribió

91 S. Schwartz, The Matrix of Modernism: Pound, Eliot and early Twentieth Century Thought, (Princeton, 1985), 4-6.

92 G. A. M. Nini, «...e su di una protesta», Azione fucina, 27 mayo (1934).

93 N. BENZI, «Sulla goliardia», Azione fucina, 27 mayo (1934).

94 N. Ciancio, «Goliarda ed apostolato», Aqione fucina, 22 diciembre (1935).

95 Su editorial florentina tuvo que lanzar una segunda y luego una tercera edición ese mismo año. 
en el prefacio: «Al autor del presente libro le parece que [...] de los miles de libros que narran la vida de Cristo no hay uno que busque en vez de demostraciones dogmáticas y explicaciones aprendidas de antemano, un mensaje adaptado al alma y añoranzas de nuestro siglo» ${ }^{96}$. Más aún, el Cristo de Papini era intensamente humano, inmerso en los problemas de su tiempo; apelando a que el hombre cotidiano y mundano que fuera a aceptar la invitación de Cristo en su viaje espiritual, sería recompensado con una libertad duradera que resulta del autoconocimiento verdadero. Es precisamente su experiencia religiosa mística y altamente personal la que hizo que Papini fuese una figura religiosa tan atractiva en su tiempo, tanto así que el fucino Filippo Piemontese no tuvo dudas en decir que «Papini es de verdad, para nosotros, el mayor y más significativo escritor en la Italia de hoy» ${ }^{97}$. Piemontese rescató además el cristianismo existencial del escritor Toscano y la mentalidad espiritual inconformista que no se retraía ante las miserias y tormentos. Aunque Papini tenía ya 53 años en ese entonces, se le presentó igualmente como la esencia de la juventud, una juventud entendida como «una evolución perennemente atormentada, la siempre operante y sobreponedora juventud del alma», su «inagotable oleaje de juventud que constantemente refresca su espíritu», lo que implicaba un «enriquecimiento continuo de experiencias». En suma, la juventud era definida como alerta, conciencia y desarrollo del sí mismo en contraste con adultos que llevaban vidas artificiales y que «dormían apaciblemente en sus existencias» ${ }^{98}$. Adicionalmente, existía conciencia de que para que la religión fuera vibrante y atractiva en los tiempos modernos, tenía que ser atrayente estéticamente y desarrollar la creatividad de la personalidad. Los intelectuales de Acción Católica reclamaban la necesidad de una «nueva concepción de espiritualidad y santidad», un vitalismo cristiano que pudiera expresar el «deseo que arde en nosotros de infundir el cristianismo en todas las formas de vida, incluyendo las más banales»; claramente distinguiendo la necesidad de sobreponerse a las formas de ascetismo religioso más tradicionales, notando que «en el pasado hubo una tendencia de conquistar la santidad a través de la renuncia a las expresiones más materiales de la vida [...] y así quemando los puentes entre el Cristianismo y las realidades más comunes» ${ }^{99}$. La nueva santidad estaba abierta a todos los hombres: «El verdadero estilo espiritual

\footnotetext{
96 G. PApini, Storia di Cristo in Cristo e Santi, (Milán, 1962), 29.

97 F. Piemontese, «Gianfalco e la giovinezza», Ažione fucina, 25 marzo (1934).

98 Ibid.

99 V. BRANCA, «Lo spirito nella vita», Azione fucina, 26 enero (1936).
} 
del siglo veinte es la santidad juvenil entre los laicos [...] que nace de la pequeñez cotidiana de la vida del mundo y, en ellos y a causa de ellos, crece y se torna robusta» ${ }^{100}$.

El ímpetu hacia nuevas formas de santidad y conciencia religiosa puede ser entendido además a través de la atención brindada a otras dos figuras emblemáticas en la Italia de entreguerra: Giovanni Bosco y Pier Giorgio Frassati. Don Bosco (1815-1888), canonizado por Pío XI en abril de 1934, fue ciertamente uno de los santos más populares en la Italia de Mussolini. Fundador de la orden de los Salesianos, fue un gran hombre de acción y excelente organizador, ejerciendo gran influencia, especialmente entre la juventud de su época. Lo hacía especialmente atrayente el que la suya «no era una santidad de purificación aislada y personal [...], sino que una santidad muy humana» ${ }^{101}$ que había «sintetizado todo lo que era excepcional de su época» y, muy significativamente, «en armonía con el ritmo apresurado de la vida moderna $»^{102}$. Don Bosco se había dado cuenta que «los nuevos tiempos requerían nuevas medidas» ${ }^{103} \mathrm{y}$ fue exaltado por algunos como un romántico, en el sentido de que reprochaba las «abstracciones arrogantes de la razón [...] en favor de la creación de un hombre concreto» ${ }^{104}$.

Pier Giorgio Frassati (1901-1925) ${ }^{105}$ había sido un miembro activo de la FUCI en Turín y en las Conferencias de San Vicente de Paul, una organización dedicada a llevar descanso espiritual y material a los sectores más deprivados de la sociedad. Su ejemplo reflejaba cuán irremediablemente insuficiente era el modelo del monje medieval viviendo solo en su celda en concentrada contemplación. Frassati fue un ejemplo muy atractivo para los laicos católicos de la época, porque no era «un intelectual, es decir, un hombre devocionado a situar su vida completa al servicio de su pensamiento, sino más bien un hombre de acción, comprometido con poner su pensamiento al servicio de su vida» ${ }^{106}$. Su santidad residía precisamente en su simplicidad y en la ordinareidad de su vida cotidiana, tan removida

\footnotetext{
100 V. Favilli, «Vincenzo Picotti», Az̨ione fucina, 8 marzo (1936).

101 Don Cojazzi, «Don Bosco: il grande Santo italiano», Azione fucina, 1 abril (1934).

102 U. Breganze, «La modernità di Don Bosco», Azione fucina, 22 abril (1934).

103 A.R. Jervolino, «Il nostro patrono», Gioventù nova, 5 abril (1934).

104 Paolo Barale, «Don Bosco e l'ottocento», Studium, n. 3 (1934).

105 Frassati fue beatificado por Juan Pablo II en 1990.

106 M.S. GiLlet O.P., «Pier Giorgio Frassati presentato come modello», Gioventù nova, 3 abril (1932).
} 
de la pomposa «santidad de estilo grandioso»; sus enseñanzas «simples, lineales, eficientes ${ }^{107}$. En suma, la espiritualidad del siglo veinte tenía que ser, como en el caso de Frassati, esencial y primordialmente aplicada ${ }^{108}$.

Existía entre estos católicos el reconocimiento que en la búsqueda de acción y regeneración personal estaban los elementos distintivos de la era moderna, inserta en un dilema dramático entre la «búsqueda de una nueva vida o muerte» ${ }^{109}$. Más aún, alertaban en contra de la falacia que proclamaba la «irreconciliabilidad de la modernidad y el Cristianismo» ${ }^{110}$. La modernidad se trataba de paradojas, contradicciones y lo efímero, pero estos católicos, en vez de esconderse en trincheras o anatemas, se involucraban entusiastas con la fluidez de los tiempos modernos. La acción y la experimentación eran posibles precisamente por el carácter trascendente del dogma católico, permitiendo que uno experimentara tan libremente. Parafraseando el famoso dictum de Marx, estos católicos creían en ofrecer una forma alternativa de modernidad, una donde todo lo que fuera sólido no se derritiera en el aire o, como proclamaban con confianza, «nunca ha existido un Cristianismo que no sea moderno» ${ }^{111}$.

107 «Pier Giorgio Frassati», Azione fucina, 1 Abril (1934).

108 A. CojAzZI, «Cristianesimo operoso», Azione fucina, 3 julio (1938).

109 Spectator (Alcide de Gasperi), «Novità e azione», Studium, n. 5 (1935).

110 Ibid.

111 Ibid. 
Resumen: Este artículo tiene por objetivo el análisis de los principales aportes a una nueva vision del catolicismo y elaboración teológica de la Federazione Universitaria Cattolica Italiana (FUCI) entre 1933 y 1939. La FUCI, la organización oficial de Acción Católica para los estudiantes universitarios de la época, fue liderada por Giovanni Battista Montini, el futuro Papa Pablo VI, entre 1925 y 1933. Hasta el día de hoy, la organización es principalmente conocida por haber formado en sus filas a gran parte de la futura clase dirigente demócrata cristiana que gobernaría Italia durante buena parte de la segunda mitad del siglo XX. Así, otros procesos de igual valor han tendido a ser dejados de lado por la historiografía. Este artículo pretende colaborar a llenar este vacío, concentrándose en la elaboración teológica de la federación, en especial la formación de la personalidad cristiana en torno a un cristianismo 'totalitario', la eclesiología de Emilio Guano y los nuevos modelos de santidad del período, todo con el fin último de ofrecer una variante de una modernidad católica para la Iglesia del período.

Palabras clave: FUCI, catolicismo social, Acción Católica, Pablo VI, Emilio Guano.

Abstract. The present study aims at analyzing the main contributions made by the Federazione Universitaria Cattolica Italiana (FUCI) to a new vision of Catholicism and theological elaboration between 1933 and 1939. As the official university student organization for Catholic Action at that time, the FUCI was led by Giovanni Battista Montini, who later became Pope Paul VI between 1925 and 1933. To date, this organization has been known to have bred most of the Christian Democratic ruling class that governed Italy for almost the entire second half of the XX century. Nevertheless, this and other processes with similar historical value have been left out of the books. This paper intends to contribute to filling such gap and focus on the theological elaboration of the FUCI. In particular, it analyzes how the organization developed a Christian personality amidst 'totalitarian Christianity', Emilio Guano's ecclesiology and new holiness models, all toward offering a variant of Catholic modernism for the Church at that time.

Keywords: FUCI, Social Catholicism, Catholic Action, Paul VI, Emilio Guano. 